\title{
2. Critical Theory and the New University: Reflections on Time and Technology
}

\author{
Peter Beilharz
}

What does critical theory bring to the discussion about universities, the institutions to which many of us have given our lives? Perhaps not a great deal, directly: we shall see. But at a broader societal level, I suspect that one of our collective shortcomings as university workers has been to fail to look for possible dots to connect between our everyday lives, our institutions, and our theoretical traditions. So this series of reflections is, in a sense, an attempt to bring critical theory back home, to connect up the personal and the societal in our lives as university workers, all this in the context of dramatic and apparently irreversible change.

Twenty years ago I published a book called Transforming Labor (Beilharz 1994). What I wanted to argue there was that the Australian Labor Party (ALP) was both the subject and the object of the transformation begun under Hawke and Keating: Labor was both the transformer and the transformed. My colleagues Mark Considine and Simon Marginson made this case for tertiary education: the process of change which began under Dawkins has cascaded on ever since. What they called the Enterprise University became a new model for Australian development (Marginson and Considine 2000). This process of transformation of the universities has continued on since, compounded by Federal intervention coupled with decreased funding, increased national competition, and increased emphasis on product standardisation coupled with claims to vocational accessibility.

My sense is that we face a dual task and responsibility in seeking to make sense of our universities today. The first is immanent, or internal, and I defer here to the wisdom of others who know better than I the empirical conditions of the 
39 universities in Australia. The only emphasis to which I would add my voice here is that the range of experience, across the Group of Eight (Go8) and the rest, and from case to case, university to university, will reinforce the importance of path dependency: there are certain common determinants, but an enormous array of local factors forming these different experiences. Some universities may move more slowly, but those more trade-exposed are compelled to seek advantage, especially via marketing and claims to novelty. Those outside the Go8 need especially to compete for students and other scarce resources such as outside funding: they commonly compete by distinction of mission, as well as by claiming Ivy-League research excellence. The second is contextual. As we seek better to make sense of universities in Australia, we should also retain the insights pioneered by Marx and Freud, that to understand any phenomenon we may need to look outside, or elsewhere. My claim here is that the transformation of everyday life in what Hartmut Rosa calls 'accelerated modernity' (Rosa 2013) means that broader trends, caught up with time and technology, will necessarily frame and form the life of the campus as we historically think of it.

This means looking, in the first instance, elsewhere, beyond the universities to the societal imperatives or logics of modernity which frame and constrain universities in the institutional sense. If we need to look closely inside the institutions, immanently, and draw due attention to universities, rather than 'the University', then we might need also to look outside the boxes, if you like, at the logics of the social system which drive and direct its subsystems (health, education, crime, housing, and so on). But there will also be more abstract logics at work here. Two of the most important themes that present themselves are time and technology. For the transformation in university life is framed and driven by trends elsewhere, from which universities cannot apparently escape (there is nothing outside society).

There is a throwaway line in Marx's Grundrisse (Marx 1857-58, 173) that could be the leitmotif here: 'Economy of time, to this all economy ultimately reduces itself.' The acceleration of time which underlies 'flexibilisation' is a major social trend which deserves our scrutiny. For there is not enough time, and too much information, 'too much civilization', as Marx puts it in the Communist Manifesto. As Zygmunt Bauman puts it, more recently, in various places in his work, the irony of overdevelopment is that where in the 19th century we (educators, people like us) believed that we could solve problems such as poverty if only we had the information, we now have so much information that we can no longer see the problem (try it - Google 'poverty' - 104 million entries in 11 seconds there's progress for you!). To state the obvious, we still need the critical culture which enables us to filter this mess of stuff; and this is what universities used to do and I think still need to do: to cultivate knowledge and interpretation rather than just gather and accumulate information. 
Flexibilisation is deeply problematical. Some academics used to joke, a way back, that the perfect university would have no students. The new joke is that it may have no teachers, just a few stragglers at help-desks in libraries that have been transformed into lounges. If we need still to use the language of rationalisation and commodification, say, after Lukács, it seems to me we also need to be looking to make sense of informationalisation, the reduction of knowledge/thinking to bite-size bits. Make it easy! Make it quick!

Tara Brabazon takes a turn at making sense of this new academic culture in Digital Hemlock (2002) and The University of Google (2007). The first book is angry, as she admits; but the issues evoked are painfully familiar: the student who asks, in dismay, 'Do I really have to go to the library?' or the essay extension request five hours before deadline from 'Miss Last Minute'. The students who take no notes, because their expectations have been socialised into powerpoint karaoke. 'I don't have any notes and I can't find anything on the web!' Or the survey responses for net-based courses - 'What are the advantages of net-based courses?' Some data from Tara Brabazon (2007, 89):

'I have gained more practical knowledge of computers and how to use them in the workforce.'

'Flexibility - can work from home; can fill in breaks; effectively can overload on units.'

'More freedom to do other things. It doesn't seem as time consuming.'

All this echoes, powerfully, with our teaching lives today; but it also issues out of a culture of complaint, and raises the spectre of nostalgia. Nostalgia, as David Lowenthal $(1985,8)$ suggested, is something like memory with the pain cut out; though our problem, generationally, might also be characterised as mourning and melancholy. We need to recognise the power of these ways of seeing, but also to be clear-eyed about the transformations that are upon us.

We all know that our students have been professionally socialised into different worlds than us, as senior academics, children of a different time and academic culture, when university experience was more like immersion (Murphy 2013). For some of us, at least, from the seventies on, universities were little communities; they offered a way of life. That may well have been a moment of privilege, a moment of exception. Whatever the case, times have changed. Some odd data from the present; today:

61 per cent of fulltime Australian students work more than they study.

University of California, Berkeley students spend 12 hours a week socialising, 11 hours using PCs for fun, 13 hours to study, six to watch TV, six to exercise,

five hours for hobbies (Murphy 2013: 50). 
Per contra, according to Zimbardo (of whom more later) Stanford students are so future-oriented, rather than hedonistic, that they don't even have time to fuck, so future-oriented are they: too busy working to score, according to The Score on Scoring: The Guidebook, (Zimbardo and Boyd 2008, 250).

As German sociologist of technology Gernot Böhme observes, the point here is not to complain about our children, but rather to face the issue of the changing forms of sociability that technologies bring. What we face here is a process of cultural transformation which also sweeps university life along with it. For example, as Böhme $(2012,6)$ observes, mobile phones bring about profound changes in habits and time sensibilities, especially among young people: for fixed appointments are practically obsolete in a world in which it is always possible to make new arrangements at the last minute. So this is less an individualised issue of 'Miss Last Minute' and more a matter of a last-minute culture which, by the way, is also how some large institutions such as universities themselves work, constantly reinventing. We might call it nowism.

So much by way of introduction. Let us shift to the more apparent question, if you come from where I come: what might a critical theory of the university look like?

There are some obvious echoes. If we were thinking of the Frankfurt School in general, Habermas would come to mind: the idea of the public sphere, the coffee shops of the 18th century, the small presses, the pre-academic informal institutionalisation of intellectual culture; another world, before state and capital transform the university, before we come to identify the university and intellectual activity, occluding the rich series of traditions associated with social movements, churches, workers and women's movements, clubs and societies that made up the strength of civil society into the 20th century.

Habermas might come to mind again, later: The Theory of Communicative Action, perhaps - a perverse thought on my part. A different spin rather on Marx too much civilisation - too much information - too much communication! The world of the sorcerer's apprentice - a world without an 'off' switch? Is that the world we inhabit? ('I emailed 5 minutes ago and you still haven't responded!')

In back of this, the first question: Adorno and Horkheimer, in Dialectic of Enlightenment. Have we arrived in the totally administered society? Well, never quite. The will to rational mastery of the world, as Cornelius Castoriadis (1985) puts it, is ahead of us but clear as a will to power; earlier, the critique of instrumental reason, the critique of positivism or positive knowledge which is information and informationalisation. 
So there are some possible connections between critical theory and the critique of universities, but let's turn elsewhere, momentarily, away from German critical theory, to East European critical theory: the now solitary figure of Zygmunt Bauman.

Bauman's most important work here is Modernity and Ambivalence (1991). ('You expect us to read a book from back then?') It is a critique of classificatory reason. This is not a new idea: not, A is not B, as we are often told; but A is B, or at least that all the phenomena of the lifeworld are open to multiple meanings or classifications. This in contrast to the reduction of knowledge to information, bite-size pieces, knowledge made easy. Teaching, especially at undergraduate levels, becomes automated, subsumed to the popular powerpoint karaoke. A is A, four dotpoints per slide, all of which can be memorised without being deeply understood; no ambiguity. Yet there is ambiguity all around. Bauman's critical sociology has more to offer than this. In various texts, including 'Tourists and Vagabonds', Bauman problematises the way in which 'liquid modernity' establishes a sense of the 'continuous present' (Bauman 1997; and see Beilharz 2001). Bauman suggests that we are guilty of 'cutting off time at both ends', absolutising the present and its promise of gratification at the expense of a decent grounding in the past and a sufficient orientation to the future. We are running on short time. 'To keep the game short means to beware long term commitments ... To forbid the past to bear on the present ... to cut the present off at both ends' (Bauman 2001, 89). For Bauman, liquid modern times generate 'nowism' as well as 'newism'; it could be that we are less postmodern than pushmodern.

Like much else in Bauman's work, this is not a strikingly original position; it draws on arguments and sensibilities given to us by the past. Bauman's concerns can also be found in, for example, Richard Sennett's Corrosion of Character, where it takes the form of the practice and culture of discontinuous reinvention. By this Sennett refers to reinventing the wheel or, in other words, eliminating the traditional stock of in-house (say) workplace knowledge that is conferred on younger workers by older workers, those possessed of more experience, so that not every challenge or issue has to be taken on as new. For Bauman, the key ambit image or enabling metaphor is that of liquid modernity. Not because our lives are actually liquid, or mercurial, but because the repertoires traditionally passed on to us hitherto are now presumed in advance to be automatically useless, obsolete, or ineffective. Bauman's approach is also sympathetic with an old marxian one, that the management of the firm would do well to recognise that capital is past, or accumulated labour: the skills and practical wisdom of the primary producers of knowledge, those on the factory floor, or coalface, or doing the teaching are themselves constitutive of value. Every time an established professional or general university worker is made 
redundant, there is an institutional and cultural loss of some proportion, a loss, to use an old term, of the kind of wisdom that hitherto-existing societies have drawn and depended on for very many years.

Bauman summons Sennett, on occasion, to argue this case, but he also returns to the insight of Christopher Lasch. According to Lasch, the disposable society now extends also to disposable identities. Identities can also now be adopted and discarded like a change of costume (Bauman 1997, 88). The rules of the game keep changing for Bauman, even in the playing. Determination to live one day at a time, and depicting daily life as a series of minor emergencies become the guiding principles of all rational life. And this is, in this way of thinking, a new rationality.

Is it really all so bad? How could these kinds of claims be empirically established? Sociologists like Bauman and Sennett and critics like Lasch take the risk of seeking to name emergent trends and possibilities. They can each be criticised, but also I think celebrated, as sociological impressionists. Claims like theirs will resonate for some of us and not for others. The baseline, for thinkers like Bauman, is that Marx was onto something fundamental with the idea of spacetime compression. As Bauman $(2000,112)$ puts it: 'Modernity was born under the stars of acceleration and land conquest, and these stars form the constellation which contains all the information about its character, conduct, and fate.' These are exactly the same issues that in a different approach concern Zimbardo, as we shall see, both in personal and in social and sociological registers.

Our students demand that what they learn should be reducible to a series of analytic propositions, correct or incorrect, tick the box. In bite-size pieces, like McNuggets. A contrast to the first course I taught in Politics at Monash, 1978, 'Revolutionary Theories' with Alastair Davidson, where the subject guide indicated that students were expected to 'read and inwardly digest'! This was only a generation ago: it feels like a world away. For it was still connected, then, to the German Enlightenment image of Bildung. (This doesn't mean that we don't have good and smart students: we do. But theirs is the world of the quick fix, Wikipedia, and multiskilling. A culture which is instrumentalised in this way cannot but have a long-term effect on the habits and sensibilities of its carriers.)

The impact of Bauman's thinking is the subject of some new work by younger minds working at Leeds in the Bauman Institute. The interest here is what Mark Davis, following Bauman, calls hurried life, for which time is the central variable (Davis 2013). We know the general themes: efficiency, individualism, want-it-all-want-it-now, the avoidance of commitment, 'you mean I need to go to the library?' The broader curiosity, which necessarily remains tentative, is indicated by the shift from analogue to digital time; and to anticipate, this should at least be enough to make us wonder (in terms of the history of culture and 
technology) whether analogue to digital is a revolution of similar proportions to that indicated by the arrival of clock-time and clock-culture. Perhaps what we need now is the contemporary version of EP Thompson's essay on 'Time-Work Discipline and Industrial Capitalism', new today.

Now Davis, working on the theme of 'hurried life' performs a neat pirouette on Bauman by reintroducing into discussion the more recent work of Philip Zimbardo. Zimbardo's, you will recall, was the famous/infamous Stanford 1971 project, parallel to the Milgram experiments, involving the use of Stanford students role-playing as prisoners and jailers, with toxic results. Zimbardo is alive and well, and centrally concerned with the issue of time. Why is time now so important? As Davis puts it, we are at risk now of losing the capacity to process information at 'less-than-internet' speeds. 'We are no longer knowledge seekers, but information data processors ... roaming from one fact to another' (Davis 2013, 15) - perhaps, contra to what we need of a new EP Thompson, we are back with Gradgrind after all. Is all we need really facts, or information? Wikipedia? Whatever the case, the trend seems to be against 'deep reading', 'deep thinking', because we lack the time. There are simply too many other competing demands and possibilities.

But of course, if we are back with Bauman, and we have too much intelligence regarding, say, poverty, then we still need the frames or paradigms or theories or theoretical culture to interpret this world, however compromising these frames or theories might be.

Davis $(2013,15)$ quotes educationalist Mark Fisher: “'Ask students to read for more than a couple of sentences and many [at A level] will protest that they can't do it. The most frequent complaint teachers hear is that it's boring."'

Boring - it's a complaint that always makes me mindful of the German equivalent - langweilig. Understanding takes a while, it takes some time, it might take a long time. Against the popular current of speed, you need to engage, to slow down. Take a leaf from the Slow Food movement. But as Davis continues, 'to be bored is to be momentarily forced out of the flow of communication that has become the lifeblood of lives assimilated into the virtual world that new technologies have made possible' (ibid). Being connected has become fundamental to Western patterns of identity formation.

Zimbardo's work on time is available in book form, as The Time Paradox, or on the net for those in a rush as The Secret Powers of Time. His work suggests that time perspectives are now notionalised by the second. The average limit in time-duration response to a computer boot up is around 60 seconds; this is the brief interval available before subjects begin to exhibit advanced states of anger. Waiting, in other words, is now understood as a waste of time, a 'waste of 
valuable seconds' (Davis 2013, 13). As part of his research, Zimbardo proposed to his subjects the hypothetical possibility of an eighth day in the week, asking respondents what they would do with it. Walk? Sleep? Read? Make love? Recover? Just be? All respondents replied that this would be a great initiative, because with an eighth day they could work harder, get more done at work and so get further ahead of their colleagues and peers. This is scary, but it is also symptomatic: for it implies the spread of that culture of individualism, in which subjects could imagine the offer to be individual, to them alone, to facilitate their own advantage rather than being collective or social in nature. To invoke the name of EP Thompson again, it is interesting to remember that there was (so to say) an eighth day before the industrial revolution - Saint Monday - and it was both collective or shared and lazy, given to recovery or inactivity.

Both Zimbardo and Bauman are in their advanced years, likely watching the clock. Their reunion here, twenty years after Bauman set the Stanford Zimbardo project to work in his 1989 classic, Modernity and the Holocaust, is timely. If, as Marx put it in 1857, 'economy of time, to this all economy ultimately reduces itself', then Zimbardo's spin would be that all life ultimately reduces itself to a matter of time. Given the absence of appropriate institutions in the public sphere for us as citizens together to discuss these matters, the logic of individualism puts us in a place where we are compelled to seek personal solutions to social problems. Senior academics, for example, exit, having given up on the prospects of voice or dreams of loyalty, or else they seek to save themselves, so to speak, through time-management schemes and individual counselling. We personalise responsibility and response to this culture which has no off-switch.

But all of this seems so immediate, so urgent, so pressing. We need also, perhaps, to slow our analysis and response down.

Let me add two more frames of reference for thinking towards the frames of time and technology, in this necessarily speculative set of reflections which is the best, at the moment, I can offer you. The first is historical, the second more properly sociological. If we are to transcend the 'culture of complaint' then we need to be open to the question of precedents in the history of technology.

Along with the work of EP Thompson, there is some good social history or history of technology and culture which might be useful here. Stephen Kern, for example, in The Culture of Time and Space 1880-1918 (1983) deploys the usual kind of images: in 1870 a traveller from Washington to San Francisco would have to reset their watch more than 200 times (Kern 1983: 12). The cult of fixed time and punctuality which we in sociology associate with Weber, The Protestant Ethic, with Baxter and Franklin - 'time is money!' - all of this is stunningly new and arbitrary, viewed from the long term or longue durée of civilisations and their histories. 
This is inherently interesting, but especially so because it comes to permeate ordinary culture and everyday life. Some alarmism, including medical alarmism, results, as in George Beard's fin-de-siècle book American Nervousness (Kern 1983, 15). Beard blamed the perfection of clocks and the invention of watches for causing nervousness wherein 'a delay of a few moments might destroy hopes of a lifetime'. Every glance at a watch for these nervous types affects the pulse and puts a strain on the nerves. Kern does not make the connection, but this sensibility echoes that of Georg Simmel in the 1903 classic 'The Metropolis and Mental Life'. As Simmel puts it, the metropolis is of significance precisely because of its effect on culture or what he here calls mental life (Geistesleben). Its basis is in the intensification of nervous stimuli, which as he famously says has as its secondary effect the blasé attitude. Speed, discontinuity, fragmentation become normalised. Money, calculation and time schedules become central. 'If all clocks and watches in Berlin would suddenly go wrong in different ways, even if only by one hour, all economic life and communication of the city would be disrupted for a long time' (Simmel 1950, 413).

All economy reduces to a matter of time - Marx; but this is also a fundamental premise for Ford, and a central premise of Fordism, which remains an active factor in the culture of the new university: the pressure toward standardisation of curriculum, delivery and staff and student expectations. Is this not a new culture of conformism? Or is it just a new version of second nature?

The culture of time is central to this process, and not only in terms of flexibilisation. But the broader effects of technological revolution are cultural: they change our common sense and expectations. Kern (1983: 91) quotes the historian Herbert Casson, writing in 1910 on the cultural impact of an earlier technological concern, that associated with the telephone. Casson noted: '... with the use of the telephone has come a new habit of mind. The slow and sluggish mood has been sloughed off ... life has become more tense, alert, vivid. It receives its reply at once and is set free to consider other matters.'

Similar issues are addressed for Europe by the German social historian Wolfgang Schivelbusch in his book The Railway Journey. The Industrialization of Time and Space in the Nineteenth Century (1977). Schivelbusch is interested in the locomotive revolution, in its preconditions and its effects. Its preconditions - and its effects, actually - include a revolution in time - in timetables, and the standardisation of time, as well as a revolution in etiquette, culture and manners. Similar local patterns are tracked by Graeme Davison in his history of time-effects in Australia (Davison 1993). So my general point here is that if we are to take on some of these big or bigger issues, then the history of technology or technology studies may be one major source or optic in the attempt to make sense of what is happening in universities today. Universities are formed by the cultures that surround them, however exactly we choose to characterise 
these. We need closer analyses of what is happening inside universities, but we are also in need of optics that are wider, and look to connecting up micro- and macro-processes of transformation.

Some of these macro-processes are likely to be opaque, or to make sense at a high level of abstraction or generality. Social change is by definition opaque, and often will make sense only after the fact. Yet we need to seek to make sense of the transformation now, midstream.

Marx was, famously, one of the first I think to articulate the idea of space/time compression. The Grundrisse (1857-58, 538), again: 'While capital ... must strive to tear down every barrier ... to exchange and conquer the whole earth for its markets, it strives on the other side to annihilate this space with time.'

Everyday life is more and more dominated by speed (Beilharz 2011). This brings us to the sociological supplement, provided here in timely manner by Hartmut Rosa in his study just to hand -Social Acceleration: A New Theory of Modernity (2013).

Rosa's book seeks to respond to the quotidian sense of accelerated life, but also to problematise it. After all, it is in principle possible that we - people like us - have an exaggerated sense of the hurried life. Rosa begins from the Marxian sensibility, that capitalism is indeed characterised by an acceleration of time. This he refracts through the work of Peter Conrad in Modern Times, Modern Places: 'Modernity is about the acceleration of time' (Rosa 2013, 14). Rosa wants to push this further, as it remains possible that this is a projection, that we project or universalise our personal sense of the hurried life onto social trends. In order to avoid too much confusion when we look at a present that seems, in some settings, to be characterised by the discontinuous reinvention of permanent reform, Rosa sets out to differentiate between the technical (or technological) compression of time (enhancements of performance in sport, transportation or computer technology) and increased social rates of change (accelerated changeovers in jobs, party preferences, intimate partners). He also draws attention to a third level of change, where the heightening of the pace of life results from an increase in episodes of action and experience per unit of time (ibid). For Rosa these trends are analytically separable: what is interesting is how they might connect. The point is not simply that everything is 'faster', but that even despite certain forms of time-gain in the last hundred years, the pace of life nevertheless seems ruthlessly to accelerate. Like Böhme, Rosa observes that time arrangements are now negotiated on the move (Rosa 2013, 127). We fear missing out, and we feel compelled to adapt. The pursuit of the full and good life leads to the hurried life (p. 134). The more means of experience (TV programs, clothes, vacations, partners) we appropriate, and the more we concentrate them in time, the richer our lives will be - the social norm indicates an increase in being 
through an increase in having (p.182). To use an older language, there is an absence of a sense of limits or hubris, as sense reminiscent of early romanticism that 'I can be everything', indeed, perhaps, serially (p. 184).

Where does all this leave us? As I indicated in the beginning, as social scientists we have our work cut out. For the immanent challenges of explaining what is happening in universities remain. But so, too, do the tasks of seeking to connect, to place these institutions socially, and to frame them with themes like those of technology and time. Universities have become paradigm cases of the kind of commodified-bureaucratic 'irrationality of rationality' that Weber feared and Kafka had nightmares about. Yet this is only a first response: they can still be subjected to clearer processes of understanding, criticism, reform and transformation.

What will universities look like in twenty years? The logic of my approach here is to suggest that we might benefit from opening the analytical optic, in order to subject universities to the same kind of critique that we would apply to other aspects of everyday life as they are transformed before us. The processes which Rosa wants us to disaggregate analytically do seem to me actually to historically coincide. Everyday life does seem to be subject to a process of accelerating change, which is accompanied in the case of the universities by powerful trends to standardisation, heightened levels of product or marketing differentiation and increasingly stringent external regulation via Canberra. Teachers, in this new world, may well be less the inspirational figures who contributed to a process of Bildungsprozess in the past, so much as instructors in a self-educative program that is increasingly DIY. In this context Australian universities struggle to position themselves for market position, seeking advantage through promotion and branding rather than through the older, now apparently redundant, model of cultivating culture or simply seeking to do good work. It is not good enough, now, to be good; everything needs to be justified, which is to say measured.

The most significant limit for academics, here, is in the diminution of our own autonomy or capacity to influence or inform future planning. This does not mean that good work will grind to a halt in the universities, but it does seem to suggest that room for manoeuvre is restricted. Analytically speaking, both the logics of state and market can be faulted here; perhaps it is their toxic combination that is most potentially destructive of what universities earlier used to be. Yet there are even larger dynamics or forces at work too, not least those of technology and its own vicissitudes. The idea of technological progress has become taken for granted, a matter of second nature for us moderns. The residual issue is what losses go together with these gains. Are the universities now self-steering systems, or are their rationalities more mixed, vexed and complicated? Truly, these would be opportune times to move forward on the critical theory of universities. 
This text is taken from Through a Glass Darkly: The Social Sciences Look at the Neoliberal University, edited by Margaret Thornton, first published 2014, this version 2015 by ANU Press, The Australian National University, Canberra, Australia. 